\title{
1 Purpose vs Performance: What does marine protected area success look like?
}

2

3 Katherine L. Yates ${ }^{a, b}$, Beverley Clarkec, Ruth H. Thurstan ${ }^{\text {d,e }}$

a School of Environment and Life Sciences, University of Salford, Manchester, United Kingdom

${ }^{b}$ ARC Centre of Excellence for Environmental Decisions, School of Biological Sciences, University of Queensland, St. Lucia, Queensland, Australia

'College of Humanities, Arts and Social Science, Flinders University, Adelaide, South Australia

${ }^{d}$ Centre for Ecology and Conservation, College of Life and Environmental Sciences, University of Exeter, Penryn, United

Kingdom

e Deakin University, School of Life and Environmental Sciences and Centre for Integrative Ecology, Burwood, Victoria,

Australia

* Corresponding author: K.L.Yates@salford.ac.uk

15 Abstract:

16 Marine protected areas (MPAs) are an increasingly deployed spatial management tool. MPAs are primarily designed for biodiversity conservation, with their success commonly measured

18 using a narrow suite of ecological indicators. However, for MPAs to achieve their biodiversity conservation goals they require community support, which is dependent on wider social, economic and political factors. Despite this, research into the human dimensions of MPAs continues to lag behind our understanding of ecological responses to MPA protection. Here, we explore stakeholders' perceptions of what MPA success is. We conducted a series of semi-structured interviews and focus groups with a diverse group of stakeholders local to a South Australian MPA. What constitutes success varied by stakeholder group, and stakeholders' stated understanding of the purpose of the MPA differed from how they would choose to measure the MPA's success. Indeed, all interviewees stated that the primary purpose of the MPA was ecological, yet almost all (>90\%) would measure the success of the MPA using social and economic measures, either exclusively or in conjunction with ecological ones. Many respondents also stated that social and economic factors were key to the MPA achieving ongoing/future success. Respondents generated a large range of novel socioeconomic measures of MPA success, many of which could be incorporated into monitoring programs for relatively little additional cost. These findings also show that success is not straightforward and what constitutes success depends on who you ask. Even where an MPA's primary ecological purpose is acknowledged by stakeholders, stakeholders are likely to only consider the MPA a success if its designation also demonstrates social and economic benefits to their communities. To achieve local stakeholder support MPAs and associated monitoring programs need to be designed for a variety of success criteria in mind, criteria which reflect

38 the priorities and needs of the adjacent communities as well as national and international conservation objectives. 
42

Highlights:

- What constitutes MPA success is complex and perceptions of success vary by stakeholder group

- Stakeholders are likely to judge the success of an MPA using criteria other than the stated designation purpose

- Local communities may fail to consider an MPA successful unless it demonstrates social and economic benefits in addition to ecological ones

- Achievement of biological success can be dependent on achievement of socioeconomic successes

- We provide a large list of novel, stakeholder generated, success indicators which could be used in monitoring programs

\section{Key words:}

Stakeholders, conservation, marine management, community engagement, biodiversity, stewardship

\section{Introduction}

Marine protected areas (MPAs) are an increasingly used management tool in marine and coastal ecosystems around the world (Pita et al., 2011). Within an MPA activities are managed or prohibited in order to protect or restore features of interest (Kelleher and Kenchington, 1992). MPAs vary in their levels of protection from multiple-use parks in which only certain activities are restricted, to strictly no-go areas where all forms of extractive, depositional and recreational uses are prohibited. Evidence for the conservation benefits of MPAs have been widely published, with the greatest benefits usually attributed to areas with the highest levels of protection (Edgar et al., 2014). MPAs have been shown to harbour increased biodiversity, as well as increases in the density and average size of previously targeted species (Alcala and Russ, 1990; Halpern, 2003). MPAs can also protect habitats, critical ecosystem functions and promote long term ecosystem resilience (Gell and Roberts, 2003; Hughes et al., 2005; Micheli et al., 2012). There is growing evidence of the ability of some MPAs to enhance fisheries through the spill-over of larvae or adult fish into adjacent or 
102 An appreciation is needed of how stakeholders, whose support is required to achieve MPA

nearby fishing grounds (Beukers-Stewart et al., 2005; Russ and Alcala, 2011; Harrison et al., 2012). Today, $>14,000$ MPAs have been designated, covering approximately $4.1 \%$ of the oceans and $10.2 \%$ of coastal areas under national jurisdiction (UNEP-WCMA \& IUCN, 2016)

While MPAs are most often designated for the purposes of biodiversity conservation, there are also social and economic consequences related to their establishment (Agardy, 1993; Farrow, 1996; Pomeroy et al., 2006; Wahle and Lyons, 2003). MPAs have been shown to benefit local communities through increased economic opportunities and alternative livelihoods provision (Rees et al., 2015), but there have also been negative effects on communities as a result of increasing conflict, or inequitable distribution of wealth (Bennett and Dearden, 2014; Christie et al., 2003). Research into the social context of MPA planning and management has been increased in recent years. In particular, there is growing evidence that stakeholder support of MPAs, including their input to the planning, designation and management processes, plays a critical role in enabling MPAs to achieve their conservation goals (e.g. Di Franco et al., 2016; Himes, 2007). However, our understanding of the human dimensions of MPAs, that is, how communities respond to MPA establishment and how these responses impact upon MPA performance, still lags behind our understanding of the ecological aspects of MPAs (Badalamenti et al., 2000; Christie, 2004).

To date, success of MPAs has generally been measured in terms of meeting biological objectives, such as increased biodiversity or biomass (Alcala and Russ, 1990; Harrison et al., 2012; Russ and Alcala, 2011). Whilst understandable, given that one of the main drivers for MPA creation is the International Convention on the Conservation of Biodiversity (CBD), this narrow view of success does not incorporate any of the human dimensions of MPAs. This narrow view also fails to take into account the CBD's revised strategy and Aichi targets, of which number 11 clearly states that protected areas should be "effectively and equitably managed", meaning that planning and management of MPAs needs to incorporate these human dimensions (UNEP 2010). conservation goals, measure success and how that varies between stakeholder groups. Whilst the different perceptions of MPA success among stakeholder groups have received 
105 some consideration (Himes, 2007), as yet unexplored is whether stakeholders' understanding

106 of the purpose of an MPA aligns with how they would measure its performance. It has been

107 argued that for MPAs to be successful, all stakeholders must be aware of and agree on MPA

108 goals and expectations (Abecasis et al., 2013; Himes, 2007). Understanding the extent to

109 which stakeholder views of success align with an MPA's stated goals will indicate the level of

110 congruence between governance institutions and local stakeholders. This understanding can

111 be useful for community engagement activities designed to build support for the MPA, as

112 well as for developing monitoring programs that capture aspects of importance to

113 stakeholders. Exploring how a group of stakeholders view both an MPA's purpose and its

114 successful performance can also provide insight into the role education/awareness raising

115 (i.e. creating understanding) of purpose can have on shaping expectations of performance.

116 Ultimately, understanding how stakeholders perceive success should feed into the

117 development of MPA designation plans and management strategies to maximise the

118 potential realisation of multiple success types and thus more equitable experience of MPA

119 success across stakeholders.

120

121 Here we explore MPA success with a diverse group of stakeholders adjacent to a recently

122 established MPA in South Australia. We consider how different stakeholder groups: 1)

123 perceive the purpose of the MPA, 2) how this perceived purpose compares to what measures

124 stakeholders would choose to judge the success of the MPA, 3) which specific indicators

125 stakeholders suggest could be used to measure the success of the MPA, and 4) how

126 stakeholders think the success of the MPA could be enhanced in the future.

127

\subsection{Study site}

129

130 South Australia has 19 multiple use marine parks designed to protect and conserve marine

131 biological diversity and marine habitats, as designated under the South Australian Marine

132 Parks Act 2007 (South Australian Government, 2007). Together these parks form the South

133 Australian Representative System of Marine Protected Areas (DEH, 2004), and encompass

134 the major ecosystems and habitat types found in South Australian waters. Each park

135 comprises a series of 'use' zones graded from general use through to highly restricted 'no go'

136 sanctuary zones (DEWNR, 2012b). The State's lead environmental agency, the Department of 
137 Environment Water and Natural Resources (DEWNR), led the process of park implementation

138 and now has oversight of park management (DEWNR, 2012a).

139

140 Achieving the 19 MPAs for South Australia was a long and protracted journey taking 14 years

141 and traversing a highly politicised process. Kirkman and Shepherd (2015) give an overview of

142 the opposition, strategies and strength mustered to resist the designation and formalisation

143 of marine parks led primarily by a powerful fishing lobby. The process commenced in 1998

144 with the South Australian state government committing to a representative system of Marine

145 Protected Areas within five years (South Australian Government, 1998). In 2001 the 2003

146 target was extended by four years in a revised vision statement \{Government of South

147 Australia, 2001 \#264\}. In 2004 the Blueprint for the South Australian Representative System

148 of Marine Protected Areas heralded an establishment date of 2010 (DEH, 2004). The state's

149 strategic plans of 2007 and 2011 both refer to the importance of and implementation of the

150 marine parks. Between 2008 and 2012 extensive work was undertaken (scientific studies,

151 planning and design) to deliver the parks. Comprehensive efforts to engage the public ran in

152 parallel with the research and design. In 2012 the parks were finally approved. However, as a

153 result of political and sectoral wrangling the original vision and design principles of

154 comprehensive, adequate and representative (CAR) coverage of habitat types across the

155 state waters was heavily compromised in the final 2012 result (Kirkman and Shepherd 2015).

156

157 The Encounter Marine Park was the first of the South Australian marine parks to be piloted

158 under the multiple-use system. It encompasses the waters off southern metropolitan

159 Adelaide and the Fleurieu Peninsula, covering an area of 3,119 km² (Fig. 1). The Encounter

160 Marine Park pilot process commenced in 2002, with a draft zoning plan released after public

161 consultation in 2005. The outer boundaries of the Encounter Marine Park were formally

162 proclaimed in 2009 after further consultation with key stakeholders. Marine park local

163 advisory groups, comprised of regional stakeholders and representatives, were established

164 that same year to provide input into the management planning process, with the current

165 Encounter Marine Park zones and associated management plans implemented in 2012

166 (Kirkman, 2013).

167 
168 The Encounter Marine Park is adjacent to Kangaroo Island and the southern Fleurieu

169 Peninsula region (comprising the Local Government Associations of Victor Harbor, Yankalilla

170 and Alexandrina). This region has traditionally been a holiday and retirement destination but

171 more recently there has been much faster population growth than that of metropolitan

172 Adelaide (ABS, 2015). Fishing, both commercial (aquaculture and wild catch) and recreational

173 are significant to the region's economy. Key target species include southern rock lobster,

174 black lip and green lip abalone, western king prawn, sardines, snapper, King George whiting,

175 southern garfish, southern calamari and blue swimmer crab. A number of commercial and

176 recreational fishing practices are used including netting (trawl, gill or mesh, hauling and dab

177 nets), line fishing (rods and lines, hand lines, longlines and droplines), traps and pots and

178 hand held implements (rakes, nets) (PIRSA, 2015).

179

180 2. Methods

181

182 We engaged stakeholders in either individual, semi-structured interviews or focus groups. In

183 many ways, focus groups and in-depth interviews are very similar and can be equally

184 effective in answering certain research questions (Crabtree, Yanoshik et al. 1993). Both

185 interviews and focus groups draw upon participants' attitudes, beliefs, and experiences

186 (Morgan and Krueger 1993). We chose to use a combination to reflect the context of the

187 groups we targeted and to maximise participation with the available resources we had.

188

189 One-to-one interviews allowed for detailed, in-depth and controlled questioning. Our

190 interviews focused on individuals who held a professional role in the designation and/or

191 ongoing management of the MPA. We interviewed them during the day, as part of their job.

192 These individuals were not necessarily geographically clustered and challenges of co-

193 ordination across multi-organisations and work schedules made bringing them together in

194 focus groups less feasible. We also anticipated they would provide substantial detail,

195 requiring more individual time, and that they may have been more constrained in the

196 information they felt they could provide if they have been in a (unavoidably) mixed-

197 institution focus group.

198 
199 Interviews took between 40 minutes to one hour and were recorded using a digital voice

200 recorder for later transcription. During the interview process additional potential participants

201 were identified. Where appropriate, these potential participants were contacted via email

202 and/or phone and invited to participate (snowball sampling). Forty-one face-to-face

203 interviews were conducted between April and November 2015.

205 Four focus groups of between 7 and 9 people were held between September and October 2062015 at three regional centres adjacent to the Encounter Marine Park. These focus groups 207 targeted input from the broader community of residents and resource users. Focus groups 208 allowed us to enable more individuals to participate than if we had only conducted 209 interviews, both because multiple individuals were participating at the same time and 210 because community groups were clustered in regional locations so logistically it was more 211 efficient to bring them together as groups. We grouped likeminded participants together 212 (conservation and commercial groupings) within focus groups because groups that consist of 213 individuals that share many of their feelings and experiences provided a more comfortable 214 space for participants to share their views (Morgan and Kreuger, 1993). Indeed several of our

215 focus group attendees said they wouldn't have been comfortable doing an individual 216 interview, but that they were amenable to contributing as part of a group.

218 Two of the research team moderated each focus group. One facilitated the group discussion

219 introducing the general issues and asking questions, allowing some flexibility in discussion, 220 and probing or interjecting to keep the conversation focussed. The second scribed key 221 emergent ideas on a screen for the group to track the discussion and managed the digital 222 recorder. While there was some latitude for free discussion of issues the moderator brought 223 the discussion back to the question set to allow for comparison on the guideline questions 224 across groups (see Supplementary Materials).

226 Selection of participants was non-random; we targeted individuals that had a record of

227 involvement in the MPA and we aimed to canvass views from a range of different 228 perspectives, including commercial and recreational sectors, conservation and volunteer 229 groups, park management, and local and state government representatives. Participants 230 were selected using a range of strategies. Park management staff and local government 
231 officials known to the researchers were approached. Sectoral, peak body (an advocacy group

232 or trade association) and conservation NGO leaders or representatives were identified via

233 internet searches, as were local volunteer and interest group networks. These groups were

234 sent an email or letter of invitation explaining the goals of the project. A non-response was

235 followed up by a phone call. Advertisements for the focus groups were placed in shop

236 windows (including tackle shops, convenience stores, and tour operators) and on notice

237 boards at shopping centres and libraries in the regional centres surrounding the Encounter

238 Marine Park. An advertisement was also placed in a local newspaper. At our request,

239 representatives of regional councils, conservation, volunteer and sectoral organisations sent

240 an email invitation to their mailing lists. To boost attendance, individuals who expressed a

241 wish to attend the focus group were requested to circulate an invitation to others in their

242 immediate network.

243

244 During both interview and focus group sessions participants were asked a series of open-

245 ended questions on the same subject matter. Questions initially explored participants'

246 knowledge of the Marine Park and their understanding of its purpose, then participant(s)

247 were asked as to their perception of benefits and costs (realised or potential) of the Marine

248 Park, whether they believed the Marine Park to be a success and what indicators they might

249 use to measure success (see Supplementary Materials 1 for list of questions). Responses

250 were recorded using a digital voice recorder.

251

252 The interviews and focus group discussions were transcribed to a Word document and later

253 uploaded to NVivo. A thematic analysis was undertaken following inductive mapping, where

254 coding and themes were directed by the content of the data. We used a 'scissor and sort'

255 technique by going through the transcript and identifying those sections of it that were

256 relevant to the research question (Stewart et al. 2007). The analysis followed a series of

257 processes, with some back-and-forth movement between them. Researchers first

258 familiarised themselves with the content of the transcripts. A coding frame was designed to

259 capture important features of the data and to respond to the research objectives. The data

260 set was then organised into codes. The codes were then read for patterns and emerging

261 themes. Qualitative responses were coded according to their content into a range of broad

262 nodes based on interview questions; perceptions of success, split into three broad 
263 categories: biological (e.g., biodiversity, habitat protection, species abundance), social (e.g.,

264 community engagement, education) and economic (e.g., tourism, fisheries); and measures

265 of success. Where directional measures of success were provided (e.g., increased

266 abundance of fish, decreased number of boat strikes on megafauna reported), these were

267 transformed into non-directional indicators. The number of individuals responding to

268 specific themes was recorded (after Stewart et al. 2007).

270 Ethics clearance was obtained from the Flinders University Social and Behavioural Research

271 Ethics Committee on 9 April 2015. All respondents were provided with participant

272 information documents before they decided if they wanted to participate, and all signed

273 consent forms prior to the interview/focus group taking place.

274

275 3. Results

276

277 Altogether, 73 people participated in the study. This consisted of 41 respondents interviewed 278 individually (Table 1 ) and 32 respondents who took part in one of four focus groups (Table 2).

279 Of those 73 individuals representation was evenly distributed across three stakeholder 280 groups: government (state and local) ( $n=24)$, conservation and community groups $(n=26)$, 281 and fisheries (commercial and recreational) ( $n=22)$. All participants had been involved, either 282 directly or indirectly, with the marine park. Engagement included: participating in the initial 283 planning process (including commenting on draft plans; acting on a local advisory group, or 284 the state-wide steering committee); conducting citizen science projects or educational 285 activities; using resources (e.g. commercial and recreational fishing and other recreation 286 activities); campaigning/advocacy; undertaking ongoing monitoring and management.

\section{$288 \quad 3.1$ Understanding the purpose of the Encounter Marine Park}

290 When asked to describe the purpose of the Encounter Marine Park, all 41 interviewees and all 291 focus groups provided a biological conservation as the primary purpose (Fig. 2). The majority 292 of interviewees $(59 \%, n=24)$ and all focus groups specifically identified habitat protection. 293 Many other respondents referred to the protection of breeding grounds (without specifying 294 for fish). 
The marine park is basically to protect the habitat of the animals that are in there, so the flora and fauna... to actually protect certain areas and samples of the habitat types that actually exist in our waters. Within that there are sanctuary zones for very specialised places as samples of those habitats types that are actually set aside for species conservation purposes. [ID 16 Environment NGOs and community groups] ...to provide protection for biodiversity in particular, and also to provide a level of protection to the marine environment and ecology from perceived or real threats. And also, the line that they trot out is also to preserve pristine habitats from potential future degradation or exploitation. [ID 32 Fishing-commercial and recreational] seaweeds and anything that's growing in the area, which is being degraded [...]. [Focus

There was also emphasis placed on the conservation of fish or fish stocks, with five interviewees (12\%) and one focus group specifically stating the protection of fish as a Groups B (Conservation interests)-Victor Harbor] purpose of the park.

317 One fifth of all interviewees ( $n=9 ; 22 \%)$ and two focus groups also identified social and/or 318 economic purposes for the marine park. Stated socio-economic purposes or 'community benefits' included primarily education, recreation and tourism. Of note, these were often referred to as a secondary or added purpose. long-term conservation benefit, that's our primary objective. The secondary aspirations really are around ensuring people get to enjoy, understand and use the Marine Park sustainably. [ID 3 State Government-Environment] 
It's about keeping what's there (wild life) and encouraging more. Looking after wildlife, basically. It's really an educational campaign as well; I think there's two parts to it. It's the saving and the learning! [ID 37 Local Government]

Primarily that marine parks are there to conserve all parts of marine biodiversity in that part of the bioregion they're in... There's a whole range of other purposes... if we

Participants stated understanding of the purpose of the Marine Park correspond tightly to the official purpose outlined in the Marine Parks Act (South Australian Government, 2007) which highlights the objects of the Act are to: "to protect and conserve marine biological diversity and marine habitats by declaring

And to assist in: can encourage some good, well thought through marine nature-based tourism opportunities and stimulate those [local] economies. [ID 6 State GovernmentEnvironment]]

348 Thus participants demonstrated that they had a very good understanding of the goals of the

349 MPA, with its primary focus on biological conservation and additional aspects of ecological sustainability and public appreciation.

\subsection{Opinions about the marine park's success}

354 When asked if the Encounter Marine Park has been a success, multiple aspects of success

355 across a biological, social and economic spectrum were generated. Responses demonstrate 356 that stakeholders have a range of interpretations of what success is, with different respondents focusing on different aspects they believe to have been or not been successful.

358 Responses also highlighted that success types could occur or accumulate over different timescales. 
361 Indeed, many people suggested that it was too early to tell ( $n=24$ interviewees, 59\%, all focus

362 groups) if the marine park had been a success. Several of those that said it was 'too early' to 363 tell made specific reference to biological successes and the need to await monitoring results. It's years down the track, I think it's too early [...]. [DEWNR] are still setting up their monitoring programs [to gather] baseline data collection inside and outside sanctuary zones. [Focus Group C Conservation interests-KI]

I think it's impossible to assess in the absence of constructive feedback from the monitoring, evaluation and reporting program. You can't make a call, because I don't know of the data, what data's being collected, what were the baselines, what's changed over time, some impacts are not going to be realised for 10, 15, 20 years. So I think that's an impossible [call]. It's going to take a long time for the data to be collected. [ID 17 Environment NGOs and community groups]

Many other respondents thought the park was already successful, at least certain aspects,

374 (17 interviewees, 41\%, and 2 focus groups). However, they focused on non-biological measures of success. Eleven interviewees (27\%) and two focus groups (one conservation, one fisheries) suggested that the existence of the Encounter Marine Park was, in its own right, a success. Eight interviewees (20\%) reported that it was a success because it had raised awareness of the marine environment and the need to conserve it. I would think in the main, the concept of marine parks has been successful..... we're now talking about something we weren't talking about before, so I think all the promotion and education around them has been very successful. [ID 40 Local Government]

386 Some respondents discussed an increased pride of place ( $\mathrm{n}=5$ interviewees) and two individuals provided specific examples of how the designation of the Encounter Marine Park already has affected the perceived value of the region. 
I know that one of the bus drivers who take bus tours around the island have said that, they've always stopped at Pelican Lagoon to show people the scenery [...], and occasionally people get out the bus and take a photo. Whereas now he stops at the same place and says, 'this is now a marine park sanctuary zone' and everyone gets out the bus to take a photo of it, just because it's a sanctuary zone. [ID 35 State As a success already, I work at Seal Bay Conservation Park [...]. We talk about the marine park and all that sort of stuff. There is nothing but positive feedback about

There was also evidence of community support for the Encounter Marine Park and the waning of negative 'noise' about it since implementation was offered as an indication of success s by eight interviewees (20\%) and one focus group. I think it has been a success since it started, but when it was proposed it wasn't. Since it having the marine park. [Visitors] just go off with great big smiles [Focus Group C Conservation interests $-\mathrm{KI}]$

MPA planning processes invariably involve some compromises, and these compromises can leave some stakeholders dissatisfied with the result. Here, it was the opinion of roughly one quarter of interviewees ( $n=10,24 \%$ ) and two focus groups that the Encounter Marine Park was not a success because of inadequate sizing/zoning within the park and some $(n=6)$ linked

414 this directly to socio-economic and political pressures. adequately for all the biodiversity conservation needs of the Encounter Marine Park, and a lot of the other marine parks, into the future. In other words I don't think we got the optimal zoning plan this time around, on this pass. [ID 6 State GovernmentEnvironment] 
"....in practical terms a lot of these sanctuary zones may actually be too small to have ecological benefits, through too much compromise in the past. And that's just purely looking from an ecological perspective, and of course there have been a lot of social, political, economic pressures to make that happen, that they are actually fairly small." [ID 26 State Government-Environment]

"...but [current sanctuary zones] are not representative. The areas you needed should have been close to the shore of the mainland, but these were too political so they didn't go through." [ID 20-commercial and recreational]

431 Thus whilst respondents suggest, in concurrence with scientific evidence, that it will take a number of years to know if the MPA has been a success in terms of as delivering the biological goals, they provide lots of evidence of it already achieving some 'social' success.

434 Maintaining the MPA long enough to enable the accrual of biological success will arguably be down to ongoing social success and local politics. Thus, identifying, understanding, enhancing and capitalising on these social success is an important aspect of MPA management.

\subsection{Measuring success}

440

441 When asked how they would measure the success of the marine park, the focus was again

442 much broader than biological conservation. Respondents provided a range of measures,

443 which we placed into three broad categories: biological, social, economic, see Table 4 for a 444 selection, and Supplementary Materials, Table 1 for a full list. Biological ( $n=37$ interviewees, 445 three focus groups) and social measures ( $n=36$ interviewees, all focus groups) were the most 446 commonly provided, though economic measures were still suggested by over half of the 447 interviewees ( $n=21$ ) and all focus groups (Table 3, Fig. 2). Most of the time interviewees and

448 focus groups provided both biological and social or economic measures of success ( $n=34$ 449 interviewees, 88\%; and three focus groups). Overall, social or economic measures of success 450 were provided by slightly more respondents than biological ones: 39 interviewees (95\%) and 451 all four focus groups provided at least one social or economic measure of success compared 452 to 37 interviewees (90\%) and 3 focus groups providing at least one biological one. Four 
453 interviewees and one focus group provided exclusively social or economic measures of

454 success, compared to just one interviewee that offered only biological measures.

455

456 That social, and to a lesser extent economic, measures of success were so frequently

457 mentioned, indeed slightly more often than biological measures, is at apparent odds with the

458 respondents stated understanding of the goals of Marine Park, which was primarily biological

459 conservation. This disparity appears even greater when the specific measures are considered:

460 there were a total of 64 separate measures of success provided, including 8 biological, 19

461 economic, 28 social and 9 social-economic measures. The much larger diversity of social,

462 economic and socio-economic measures may reflect the complexities of socio-economic

463 success, but it may also represent respondent's greater understanding of the socio-economic

464 context, in which they are immersed, than the more removed biological one.

465

466 When suggesting measures, many respondents provided a particular direction by which they

467 would determine success or failure (e.g., increased abundance of fish versus decreased

468 abundance or no change over time). Because the direction by which success is measured has

469 the potential to vary by stakeholder group or by individual, listed measures are provided as

470 non-directional (Table 4 and Table S1, Supplementary Materials; see Discussion section 4.2).

471

472 Suggested biological measures of success included: number of species present, size and 473 abundance of fish, and degree of habitat damage.

474

475

Sea grasses coming back, more fish coming back in, more marine life - coming back to

476

477

478

479

480

what it was, I guess. Has it improved under the water since it's been implemented? I don't know. So [an increase in the extent] of sea grasses. With [the sea grasses] there it would

481

482 attract the marine life back in again: everything that lives out in the sea... It's not just fish, I suppose the quickest measurement is the numbers of the fish stock overall [inside and outside the marine park]. [ID 24 Local Government]

483

... whether species increased or habitat improved, stuff like that, and you may compare it

484 to similar places that aren't protected. [ID 38 State Government-Environment] 
501

502

503

504

505

506

507

508

509

510

511

512

513

To be able to demonstrate that we've preserved or protected or done something to conserve biodiversity, we have to measure some biophysical parameters of marine parks, so some measure of how well they're doing with respect to the biodiversity that occurs there, and the conditions of the environment that occurs there. [ID 21 State Government-Environment]

Suggested social measures of success included: levels of community support expressed for the marine park, levels of restrictions on activities considered harmful to conservation objectives, levels of voluntary compliance/violation of rules, levels of stewardship and community involvement in park management, amount of positive commentary about the park in the media, and level of incorporation of the marine parks into local school curriculum.

That's another way to measure success, and of course the other thing is, to measure community buy-in: does the community support the marine parks, and does the active community support the marine parks? [ID 19 Fishing interests-commercial and recreational]

Compliance is an issue I think [...]; compliance would be a good indicator [of success]. [Focus Group C (Conservation Interests) - KI]

Looking at the community involvement, so number of volunteers, even vandalism to signs... [ID 3 State Government-Environment]

Suggested economic measures of success included: quantity of catch (fisheries), change in tourism activity, value of real-estate adjacent to the park, development of new businesses, revenue of existing businesses.

Economically, if commercial fishing [is able] to continue into the future, that would be good; that would be the proof of the pudding. There should be a flow from marine parks into the fishing areas. [ID 27 NGO and community groups]

Tourism - the number of tourists could be a measure, and the number of residents, but how do you know if migration is due to the marine park? [ID 20 Fishing interests-

$514 \quad$ commercial and recreational] 
41

If you look at interstate examples where there's been marine parks in place for some time, you'll start to see - even in real estate ads - 'great house next to a marine park'. You know you've got a measure of success when someone's using it as an asset in a real estate sale. [ID 35 State Government-Environment]

The next thing to look at would be economic, and I think the measure of that would be seeing allied industries or business areas grow, or at least not decline. I think the difficulty with that is because there are such fine linkages between what a marine park means and how that actually connects to the business of a hardware and fishing tackle store, or a fish and chip shop or even the fuel station, makes it very difficult. [ID 28 Local Government]

As well as highlighting that respondents considered a much greater variety of success measures than biological, responses also demonstrate an understanding of the fact that measuring or demonstrating some these successes, or lack of them, will be very challenging.

\subsection{Weighting of measures}

Not all successes are equal and knowing which ones are more valuable to stakeholders can help guide discussion and inform the inevitable trade-offs when planning and managing MPAs. When asked to identify the most important measurement criteria to gauge success of the Park, nearly one quarter of our interviewees $(n=10 ; 24 \%)$ explained that the environmental (biological/ecological) criteria were on a 'level playing field' with socioeconomic. They could not differentiate a weighting between them as they believed the criteria were interconnected, highlighting the need realise one success type to support achievement of another. It's a hard one, as they're so interlinked. As a scientist I'm of course inclined to say the ecological thing is important, but of course you can't have ecological outcomes without support from the community and general public. [ID 26 State Government-Environment] I would put them all equally. All of them have a different outcome, a different reason for needing that data. [ID 31 Local Government] 
546

547

548

549

550

551

552

553

554

555

556

557

558

559

560

561

562

563

564

565

566

567

568

569

570

571

572

573

574

575

576

577 Thus, while our respondents universally acknowledge the primary purpose of the Marine Park

578 to be biological, they certainly do not universally think that biological success is the most

It's really tricky because they're so intertwined. Without the ecological outcomes it will be harder to garner the community support, and without community support you're going to have compliance issues, which can undermine ecological outcomes. [ID 13 Local Government]

Nine interviewees (22\%) said that while they would select environmental

(biological/ecological) measures as the most important, they also recognised the substantial importance of socio-economic measures.

It comes back to the purpose [of the park]... [Top ranked would be] the number of species identified as significant, are they still there, and are those habitats still functioning as they were found? Then it'd be the social. [ID 17 NGO and community groups]

Number one has to be - because we can't measure the success of the parks without this number one has to be some biophysical measure of the trends of protecting biodiversity. However, I wouldn't put it so far ahead that we exclude doing anything else. So then equal to that I think we need those measures of social, economic and even cultural change, and I'd rank those equally around trying to understand how the community's tracking and where it wants to go. [ID 21 State Government-Environment]

Five interviewees (12\%) argued that the socio-economic success measures were the most important because of the wider implication that they have.

Socio-economic is the most important. That's because of the politics.... We need to be able to demonstrate very quickly that this has had a neutral impact [ID 3 State Government-Environment]

.......if we don't have that second bit, the fact that people appreciate it and understand it, then they're not going to protect things for very long because we'll get rid of them. So I suppose to make sure that they are there, we need to concentrate on the social bit, even if that may not technically be the most important thing. The political side of things is [therefore] probably more important than the environmental side of things. [ID25 State Government-Environment] 
important. Rather respondents repeatedly identified an appreciation of the need to achieve social success in order to obtain biological success, and the importance of politics in doing so.

\section{$583 \quad 3.5$ How to increase the success of the MPA}

584

585 All suggestions of increasing the future success of the MPA related to social and economic 586 aspects of the Encounter Marine Park and suggest an inherent understanding that success of 587 all types requires socio-economic investment. Many interviewees and all three focus groups identified interwoven aspects of enhanced communication, education, awareness raising, and community engagement/outreach and as being central to improving the success of the MPA. Communication, in particular, was considered essential for effectively engaging the community and improving stakeholder buy-in. Our respondents discussed three main aspects

592 of communication that need improving to increase the Marine Park's success: improving

593 information outputs to publicise the Encounter Marine Park-to sell the concept of the marine park and to highlight successes; publicising management and monitoring program results because monitoring data is essential to promote the park's achievements; and the need for transparency and openness. protecting it'. That's something that's missing at the moment, a lot of the marine parks' information is purely about the rules, where you can and can't fish, and it's all about recreational fishing, it's not about 'these are the special things that are the reasons we've got these sanctuary zones here'. It needs to be about concentrating on what you can do, rather than what you can't. [ID 25 State Government-Environment] so the results do become known. I think the impacts [of activities] need to be monitored, and we'd like to hear the results of that as well. [ID 27 Environment NGOs and community groups] 

on a public website so that people of any level of interest can have access to the information... It may be a failure, but let's be open about that and let's have a look at that information. [ID 18 Local Government]

615

616 Discussions around education involved both the more formal, traditional education routes,

617 such as working directly with schools, and more general awareness raising through

618 community engagement and outreach.

619

620

621

622

623

I've always been a big one for educating the young people, so getting into schools and

624

625

626

627 setting up a proper marine education program that addresses the needs for teachers to 628

629 Multiple respondents ( $n=8$ interviewees, 20\%; and 2 Focus Groups) acknowledged that in the 630 end everything comes back to money. Regional economic development within communities

631 attributable to the marine park (such as tourism ventures or eco-labelling of food products)

632 were felt would help engender support for the Encounter Marine Park. In addition, it was 633 considered that adequate resourcing will be essential to sustain management functions of 634 the Encounter Marine Park.

635 I don't think there's enough discussion of what are the commercial opportunities that will ultimately contribute to sustainable resource use... I'm thinking of the tourism side of things, I'm not talking about commercial fishing... In the marine park you do need to seriously look at what are the commercial tourism opportunities, both to start the process 641 
642

643

644

645

646

647

648

649

650

651

652

653

654

655

656

657

658

659

660

661

662

663

664

665

666

667

668

669

670

671

672

673

674

675

Funding, everything hinges on funding; whether we look at stewardship, or compliance or the monitoring side, all of that needs to be kept up or increased and that requires funding. [ID 26 State Government-Environment]

If there were more resources available you could do more from a compliance point of view, you could do more from an education point of view: you could put on more activities for kids, you could put in more interpretive signs if that's what you decided you needed. But everything is now limited by resources. [ID 35 State Government-Environment]

That respondents provided only socio-economic means to increase future success of the park reflects the reality that MPAs are social constructs that need social, political, and economic support to be successful. Results demonstrate the importance of the human dimensions, the need to raise awareness so that people will value the Marine Park and in turn galvanise enough political support to ensure sufficient and ongoing funding for education, monitoring and compliance. The link to politics for the success of the park, both past (including original designation) and ongoing is inferred multiple times ( $n=13$ interviewees and all focus groups) ...in my cynical moments I wonder how much it was partly a political choice to have a park there simply because of its proximity to Adelaide, and there's a lot of people on the Fleurieu too. [ID 1 Environment NGOs and community groups]

...from a management point of view, if your political leaders see your program as that 4 fantastic then they're likely to keep funding it into the future. [ID 3]

66 If we have a political environment that is regressive with marine parks with respect to 67 marine parks, then I think that it could go pear-shaped pretty quickly. If the current 68 political environment prevails then I think the future looks good. [ID 6 State GovernmentEnvironment]]

71 The 10-year review will be challenge if the political animosity has not been resolved... if you had bipartisan support from both the major parties, that would just make things so much easier... [ID 13 Local Government] 


\section{4. Discussion}

678

679 This study examined MPA success, using the Encounter Marine Park in South Australia

680 established in 2009. Through semi-structured interviews and focus groups with 73

681 respondents from three main stakeholder groups, we found that stakeholder understanding

682 of the purpose of a park differs from how they would measure its successful performance.

683 We found that stakeholders consider that social and economic aspects of MPAs to be as

684 important for current success as biological aspects. Moreover, stakeholders were united in 685 expressing that future success of the MPA depends on social and economic aspects, and they 686 highlighted the role of politics in determining success.

687

688

\subsection{Perceptions of purpose versus perceptions of performance}

689

690 Success is a complex, multifaceted concept, which very much depends on an individual's perspective. In the literature, MPAs, in general, are considered successful when they are seen

692 to have achieved/be achieving their purpose (i.e., their stated aims and objectives) (Pollnac et 693 al., 2001; Pomeroy et al., 2005). All of the respondents in this study (interviewees and focus 694 group participants) identified the purpose of the Encounter Marine Park to be biological. Only 695 around one quarter of respondents also provided secondary social or economic purposes. 696 However, when asked how they would measure the Park's success, only one respondent 697 provided exclusively biological measures. All other respondents, both interviewees and focus 698 group participants, specified social and or economic measures of success, exclusively or in 699 addition to biological measures. Stakeholders identifying social and economic measures of success is, in itself, unremarkable. That MPAs can have substantial social and economic implications, both positive (Alder et al., 2002) and negative (Mayo-Ramsay, 2014; Yates and

702 Schoeman, 2015), is well established. What is interesting, and important, is that whilst our respondents clearly identified the primary purpose of the designation of the park as

704 biological conservation, they would measure if the MPA was successful based on social and 705 economic effects as readily as the biological ones. For some respondents these economic and social measure of success were more important than the ecological ones, despite the ecological measures relating directly to the goals of the MPA. Thus, it seems that what 
stakeholders consider 'success' may not always be related to the purpose the MPA was designated for, even when stakeholders have been educated as to what that purpose is.

\section{$711 \quad 4.2$ Measuring success}

712

713 Quantifiable measures (indicators) are an essential aspect of effective monitoring programs,

714 enabling us to assess if MPAs have achieved their objectives. While the literature on

715 ecological and biophysical indicators is extensive, the literature on social and economic

716 indicators has lagged behind and is generally less well developed (Pomeroy et al. 2006). 'Best

717 practice' guidelines exist for socio-economic indicators, which are intended for general use

718 and are presented as broad guidance regarding the development of such indicators (e.g.,

719 Bunce et al. 2000, Hockings et al. 2006, but see Pomeroy et al. 2004). In contrast to these

720 broad guidelines, respondents here were often quite specific when suggesting indicators of

721 success.

722

723 Biological measures of success suggested by respondents corresponded closely to standard

724 indicators published in the literature and already commonly used in MPA monitoring (e.g.

725 species abundance, species richness). However, many of the respondent-proposed social and

726 economic measures were novel and innovative, with most of the suggested measures not

727 previously published (Table 4, Table S1). Suggestions ranged from measures that could be

728 implemented and monitored relatively easily and with little cost (e.g., the extent of

729 educational signage around the marine park, amount of funding allocated for marine park

730 management), to measures that would be more challenging and costly to obtain (e.g., levels

731 of misinformation transmitted by local media over time). Incorporating stakeholder-derived

732 indicators into monitoring programs enables the collection and communication of

733 information that directly relates to aspects of success that stakeholders care about. As well as

734 providing useful information on different aspects of success about which managers may not

735 have thought, using stakeholder suggested measures of success acknowledges stakeholders

736 views, makes the achievement of more equitable success more likely, and encourages buy-in

737 and future support.

738 
739 Indicators tend to be non-directional (e.g., neither decreasing or increasing over time),

740 however, determining the direction of the measure for quantifying success is important in

741 practice, as perceptions may differ from place to place and among stakeholders. For

742 example, having increased 'levels of scrutiny faced by commercial development applicants

743 within or adjacent to the MPA' would be considered a success by local conservation groups,

744 but may not be considered a success by a state government department tasked with

745 expanding rural development initiatives. The same could be said for coastal real estate or

746 rental prices; increases in price might be considered a success by older generations, who are

747 generally property owners, but not for younger residents who may subsequently be priced

748 out of their local home-owners market.

749

750 The level of importance placed upon specific success measures may also vary by community

751 or among stakeholders. The Encounter Marine Park is in a post-implementation,

752 management and monitoring phase. Ideally this management and monitoring should take

753 into account perspectives of different stakeholders and report back on the realised

754 achievements of the park should incorporate how different groups perceive success. Results

755 show that here, this will mean highlighting and enhancing the social and economic successes

756 as much as the ecological. Moreover, this study shows that while the use of standard

757 indicators may be appealing to resource-limited governments, tailoring indicators so they are

758 relevant to local stakeholder groups and developing a broader suite of indicators may be

759 needed to effectively capture the diversity of stakeholders' perceptions of success.

760

761 Stakeholder participation in MPA management has to be meaningful to be effective, with

762 clear pathways to impact decisions (Yates, 2018). The co-development of indicators that truly

763 represent the priorities of local stakeholders is one way of enabling meaningful participation,

764 but it will only be achieved through detailed consultation with those stakeholders. While this

765 may be costlier in the short-term, it also provides a number of benefits for management.

766 Consulting stakeholders on how to measure the success of a MPA and incorporating their

767 suggestions gives stakeholders a voice, encourages participation in management and, when

768 the measures are used, demonstrates that stakeholder input is valued (Elliott et al., 2001;

769 Lundquist and Granek, 2005; McCay and Jones, 2011) all of which should increase support for

770 the MPA. Understanding stakeholder's perceptions of success also gives an insight into their 
771 disparate expectations, which can inform management as to those expectations through

772 targeted communication. Given how important community support is for achieving MPA

773 goals (Bennett and Dearden, 2014; Bernstein et al., 2004; Charles and Wilson, 2009), we

774 suggest ensuring sufficient resources are available to develop measures in conjunction with

775 stakeholders and that incorporating suggestions into monitoring plans should be a priority.

776

$777 \quad 4.3$ Variation among stakeholder groups

778

779 Perceptions as to what constitutes MPA success vary by stakeholder group (Himes, 2007).

780 Our findings here support other studies that have shown a divergence within communities

781 between groups with resource extraction interests (e.g. fisheries) and groups who prioritise

782 conservation (Pomeroy et al., 2006, Carcamo et al. 2014). Here, stakeholders from the

783 fishing industry were more likely to identify economic measures of success than conservation

784 groups. This is no surprise. Fishers are the group most directly affected by the spatial

785 restrictions of MPAs, which can both reduce their income and increase their costs (Yates,

786 2014). Fishers, being directly financially dependent on access to marine resources are

787 justifiably concerned about the economic implications of MPAs. For many stakeholders

788 fostering sustainable use is the priority (Carcamo et al. 2014). Conservation focused

789 stakeholders not directly dependent on access to marine areas for their livelihood can afford

790 to prioritise the more expansive goals of biodiversity conservation and ecosystem resilience.

791 Neither an economic or ecological priority is more 'correct', they simply reflect the context of

792 a particular stakeholder. An important part of MPA planning and management is

793 understanding and incorporating the priorities of different stakeholder groups, mitigating

794 conflict where possible and meeting objectives at minimum cost (Pendred et al., 2016).

795 Involving stakeholders can contribute to better decisions (Pendred et al., 2016) and reduce

796 the cost of MPA planning solutions (Yates and Schoeman, 2015).

798 Whilst some priorities and measures of success vary between stakeholder groups, we also

799 found substantial overlap. Members of the fishing community identified biological measures

800 of success, conservation stakeholders identified economic and social measures, and

801 government representatives had the broadest view of success (including measures from all

802 categories). Identification of shared perspectives on success can be a means to resolve 
803 conflict, as well as opening up opportunities for innovate solutions to conflict that may result

804 in greater acceptance and meeting of MPA biological goals). Thus, understanding that

805 stakeholders may identify measures of success over and above the purpose of the MPA and

806 understanding how those measures of success vary between groups are essential when

807 planning and managing an MPA. As is acknowledging, as our respondents did, that some

808 successes, primarily biological, are at least partially dependent on achieving other types of

809 success, primarily socio-economic and political.

810

811 Effectively communicating monitoring results back to stakeholders is essential to

812 acknowledge and maximise appreciation of successes, as highlighted by respondents in this

813 study. Communication is also important for highlighting where more work is needed to

814 improve the success of the MPA and encouraging communities to contribute. Provision of

815 information around compliance, success stories, and opportunities for engagement were

816 specific aspects requested by our respondents. An absence of information dissemination

817 leads to disquiet and uncertainty, and cynicism. Knowing how stakeholders perceive success

818 will enable communication efforts to focus on aspects that matter most to stakeholders.

819

820 Of course, perceptions of success may change over time. It is therefore important to monitor

821 community perception across all stages of MPA development (from implementation

822 onwards). With this in mind it will be beneficial to return to the Encounter Marine Park

823 communities in five and 10 years' time to reassess the perceptions of this group of people to

824 see whether or not their perceptions have changed and what can be learned from that,

825 including which have been the most robust socio-economic indicators of success.

826

827

828 5. Conclusion

829

830 What constitutes MPA success is dependent on individual perspectives and local context.

831 Meeting stated objectives is obviously an important aspect of success, yet even where MPAs

832 are designed to achieve one particular goal and that goal is effectively translated to members

833 of the community, the community will likely judge MPA success across a range of different

834 measures, including those that the MPA was not necessarily designed for. Achievement of 
835 these different measures of success can be interdependent. Therefore, a broad range of

836 measures of success need to be considered when designing an MPA and developing its

837 monitoring program, including social and economic measures, even if the goal of the MPA is

838 entirely biodiversity conservation. Ideally these measures (indicators) should be developed in

839 conjunction with the stakeholder community.

840

841 Communication is the key to attain and maintain the support of communities adjacent to

842 marine parks and thus is an essential aspect of future MPA success. Communication efforts

843 should focus on the issues relevant to those local communities/stakeholder groups, including

844 sharing monitoring results that capture stakeholder relevant indicators of success. Ideally this

845 should be considered at the early stages of MPA designation to maximise the collection and

846 dissemination of as many 'success stories' as possible, and to achieve early wins and local

847 buy-in.

848

849 In the end, there are no short cuts when it comes to gaining broad stakeholder buy-in for an

850 MPA. Investment in understanding and incorporating stakeholders throughout planning and

851 management phases is essential, and part of that should involve gathering different

852 stakeholder's perceptions of success. Success (or failure) will consist of a multitude of

853 aspects, many of which will be less tangible and thus more difficult to measure with

854 quantitative monitoring. Capturing stakeholder's perceptions and stories of success (or

855 failure) will help build a fuller picture of the impacts of a given MPA and allow for more

856 holistic adaptive management efforts.

857

858 Acknowledgements

859

860 Our thanks go to all the respondents that participated in this study. In particular, the DEWNR

861 Marine Parks Team for their on-going support. The Wildlife Conservation Fund, DEWNR,

862 funded this project. 
865

866

867

868

869

870

871

872

873

874

875

876

877

878

879

880

881

882

883

884

885

886

887

888

889

890

891

892

893

894

895

896

897

898

899

900

901

Abecasis, R.C., Schmidt, L., Longnecker, N., Clifton, J., 2013. Implications of community and stakeholder perceptions of the marine environment and its conservation for MPA management in a small Azorean island. Ocean \& Coastal Management 84, 208-219.

ABS, 2015. Regional Population Growth. 3218.0, Australian Bureau of Statistics. Australian Bureau of Statistics, Canberra.

Agardy, M.T., 1993. Accommodating ecotourism in multiple use planning of coastal and marine protected areas. Ocean \& Coastal Management 20, 219-239.

Alcala, A.C., Russ, G.R., 1990. A direct test of the effects of protective management on abundance and yield of tropical marine resources. ICES Journal of Marine Science 47, 4047.

Alder, J., Zeller, D., Pitcher, T., 2002. A method for evaluating marine protected area management. Coastal Management 30, 121-131.

Badalamenti, F., Ramos, A., Voultsiadou, E., Sánchez Lizaso, J., D’anna, G., Pipitone, C., Mas, J., Ruiz Fernandez, J., Whitmarsh, D., Riggio, S., 2000. Cultural and socio-economic impacts of Mediterranean marine protected areas. Environmental Conservation 27, 110-125.

Bennett, N.J., Dearden, P., 2014. Why local people do not support conservation: Community perceptions of marine protected area livelihood impacts, governance and management in Thailand. Marine Policy 44, 107-116.

Bernstein, B., ludicello, S., Stringer, C., 2004. Lessons Learned from Recent Marine Protected Area Designations in the United States. A Report to: The National Marine Protected Areas Center NOAA, California.

Beukers-Stewart, B., Vause, B., Mosley, M., Rossetti, H., Brand, A., 2005. Benefits of closed area protection for a population of scallops. Marine Ecology Progress Series 298, 189-204.

Bunce, L., Townsley, P., Pomeroy, R., Pollnac, R., 2000. Socioeconomic manual for coral reef management. Australian Institute of Marine Science, Townsville, Queensland.

Cárcamo P. F., Garay-Flühmann, R., Squeo, F. A., Gaymer, C. F., 2014. Using stakeholders' perspective of ecosystem services and biodiversity features to plan a marine protected area. Environmental Science \& Policy 40, 116-131,

Charles, A., Wilson, L., 2009. Human dimensions of marine protected areas. ICES Journal of Marine Science 66, 1-15.

Christie, P., 2004. Marine protected areas as biological successes and social failures in southeast Asia, In: Shipley, J.B. (Ed.), Aquatic Protected Areas as Fisheries Management Tools, pp. 155-164.

Christie, P., McCay, B.J., Miller, M.L., Lowe, C., White, A.T., Stoffle, R., Fluharty, D.L., McManus, L.T., Chuenpagdee, R., Pomeroy, C., Suman, D.O., Blount, B.G., Huppert, D., Eisma, R.L.V., Oración, E., Lowry, K., Pollnac, R.B., 2003. Toward developing a complete understanding: A social science research agenda for marine protected areas. Fisheries 28, 22-26. 
Crabtree, B. F., M. K. Yanoshik, W. L. Miller and P. J. O'Connor (1993). Selecting Individual or Group Interviews. Successful Focus Groups: Advancing the State of the Art. D. L. Morgan. Thousand Oaks, California, SAGE Publications, Inc.: 137-150.

DEH, 2004. Blueprint for the South Australian Representative System of Marine Protected Areas. Department for Environment and Heritage, Adelaide.

DEWNR, 2012a. Encounter Marine Park Management Plan 2012. Department of Environment, Water and Natural Resources, Government of South Australia, Adelaide.

DEWNR, 2012b. South Australian Marine Parks Network Explanatory Document: An explanatory document to support the public review of marine park draft management plans, Adelaide.

Di Franco, A., Thiriet, P., Di Carlo, G., Dimitriadis, C., Francour, P., Gutiérrez, N.L., Jeudy de Grissac, A., Koutsoubas, D., Milazzo, M., Otero, M.d.M., Piante, C., Plass-Johnson, J., Sainz-Trapaga, S., Santarossa, L., Tudela, S., Guidetti, P., 2016. Five key attributes can increase marine protected areas performance for small-scale fisheries management. Scientific Reports 6, 38135.

Edgar, G. J., Stuart-Smith, R. D., Willis, T. J., Kininmonth, S., Baker, S. C., Banks, S., Barrett, N. S., Becerro, M. A., Bernard, A. T. F., Berkhout, J., Buxton, C. D., Campbell, S. J., Cooper, A. T., Davey, M., Edgar, S. C., Försterra, G., Galván, D. E., Irigoyen, A. J., Kushner, D. J., Moura, R., Parnell, P. E., Shears, N. T., Soler, G., Strain, E.M.A., Thomson, R.J., 2014. Global conservation outcomes depend on marine protected areas with five key features. Nature 506, 216-220.

Elliott, G., Wiltshire, B., Manan, I.A., Wismer, S., 2001. Community participation in marine protected area management: Wakatobi National Park, Sulawesi, Indonesia. Coastal Management 29, 295-316.

Farrow, S., 1996. Marine protected areas: emerging economics. Marine Policy 20, 439-446.

Gell, F. R., Roberts, C. M., 2003. Benefits beyond boundaries: the fishery effects of marine reserves. Trends in Ecology \& Evolution 18, 448-455.

Halpern, B. S., 2003. The impact of marine reserves: Do reserves work and does size matter? Ecological Applications 13, S117-137.

Harrison, H.B., Williamson, D.H., Evans, R.D., Almany, G.R., Thorrold, S.R., Russ, G.R., Feldheim, K.a., van Herwerden, L., Planes, S., Srinivasan, M., Berumen, M.L., Jones, G.P., 2012. Larval export from marine reserves and the recruitment benefit for fish and fisheries. Current Biology 22, 1023-1028.

Himes, A.H., 2007. Performance indicators in MPA management: Using questionnaires to analyze stakeholder preferences. Ocean \& Coastal Management 50, 329-351.

Hockings, M., Stolton, S., Leverington, F., Dudley, N., Courrau, J., 2006. Evaluating effectiveness: A framework for assessing management effectiveness of protected areas. 2nd Edition, IUCN, Gland, Switzerland and Cambridge, UK.

Hughes, T. P., Bellwood, D. R., Folke, C., Steneck, R. S., Wilson, J., 2005. New paradigms for supporting the resilience of marine ecosystems. Trends in Ecology \& Evolution 20, 380386. 
Kelleher, G., Kenchington, R., 1992. Guidelinesfor Establishing Marine Protected Areas. A. Marine Conservation and Development Report. IUCN, Gland, Switzerland.

945

946

947

948

949

950

951

952

953

954

955

956

957

958

959

960

961

962

963

964

965

966

967

968

969

970

971

972

973

974

975

976

977

978

979

980

981

982

983

Kirkman, H., 2013. Choosing boundaries to marine protected areas and zoning the MPAs for restricted use and management. Ocean \& Coastal Management 81, 38-48.

Kirkman, H., Shepherd, S.A., 2015. Further efforts to protect biodiversity in coastal waters of South Australia. Ocean \& Coastal Management 104, 115-123.

Kusumawati, I., Huang, H.-W., 2015. Key factors for successful management of marine protected areas: A comparison of stakeholders' perception of two MPAs in Weh island, Sabang, Aceh, Indonesia. Marine Policy 51, 465-475.

Lundquist, C.J., Granek, E.F., 2005. Strategies for successful marine conservation: integrating socioeconomic, political, and scientific factors. Conservation Biology 19, 1771-1778.

Mayo-Ramsay, J., 2014. Measuring the economic, social, cultural and environmental value of Marine Protected Areas in New South Wales, 23rd NSW Coastal Conference, Ulladulla, NSW.

McCay, B.J., Jones, P.J.S., 2011. Marine protected areas and the governance of marine ecosystems and fisheries. Conservation Biology 25, 1130-1133.

Micheli, F., Saenz-Arroyo, A., Greenley, A., Vazquez, L., Espinoza Montes, J.A., Rossetto, M., De Leo, G.A., 2012. Evidence that marine reserves enhance resilience to climatic impacts. PloS One 7(7), e40832.

Morgan, D. L. and R. A. Krueger (1993). When to Use Focus Groups and Why. Successful Focus Groups: Advancing the State of the Art. D. L. Morgan. Thousand Oaks, California, SAGE Publications, Inc.: 3-19.

Pendred, S., Fischer, A., Fischer, S., 2016. Improved Management Effectiveness of a Marine Protected Area through Prioritizing Performance Indicators. Coastal Management 44, 93-115.

PIRSA, 2015. Status of South Australian Fisheries Report. South Australian Fisheries Management Series, Paper number 69. Primary Industries and Regions SA, Adelaide.

Pita, C., Pierce, G.J., Theodossiou, I., Macpherson, K., 2011. An overview of commercial fishers' attitudes towards marine protected areas. Hydrobiologia 670, 289-306.

Pollnac, R., Crawford, B., Gorospe, M., 2001. Discovering factors that influence the success of community-based marine protected areas in the Visayas, Philippines. Ocean \& Coastal Management 44, 683-710.

Pomeroy, R., Mascia, M., Pollnac, R., 2006. Background paper 3: Marine Protected Areas, the Social Dimension In FAO Expert Workshop on Marine Protected Areas and Fisheries Management: Review of Issues and Considerations. FAO, pp. 149-275, Rome.

Pomeroy, R.S., Parks, J., Watson, L., 2004. How is Your MPA Doing? A Guidebook of Natural and Social Indicators for Evaluating Marine Protected Areas Management Effectiveness. IUCN, Gland, Switzerland and Cambridge, UK.

Pomeroy, R.S., Watson, L.M., Parks, J.E., Cid, G.A., 2005. How is your MPA doing? A methodology for evaluating the management effectiveness of marine protected areas. Ocean \& Coastal Management 48, 485-502. 
984

985

986

987

988

989

990

991

992

993

994

995

996

997

998

999

1000

1001

1002

1003

1004

1005

1006

1007

1008

Rees, S.E., Mangi, S.C., Hattam, C., Gall, S.C., Rodwell, L.D., Peckett, F.J., Attrill, M.J., 2015. The socio-economic effects of a Marine Protected Area on the ecosystem service of leisure and recreation. Marine Policy 62, 144-152.

Russ, G.R., Alcala, A.C., 2011. Enhanced biodiversity beyond marine reserve boundaries: the cup spilleth over. Ecological Applications 21, 241-250.

South Australian Government, 1998. Our Seas and Coasts: A Marine and Estuarine Strategy for South Australia. Marine and Estuarine Steering Committee, Adelaide.

South Australian Government, 2007. Marine Parks Act 2007.Adelaide. https://www.legislation.sa.gov.au/LZ/C/A/MARINE\%20PARKS\%20ACT\%202007/CURRE NT/2007.60.UN.PDF (accessed 23 October 2017).

Stewart, D. W., P. N. Shamdasani and D. W. Rook (2007). Analyzing Focus Group Data Focus Groups. D. W. Stewart, P. N. Shamdasani and D. W. Rook. Thousand Oaks, California, SAGE Publications, Ltd.: 109-133.

UNEP (2010) 'Aichi Biodiversity Targets', United Nations Conservation on Biological Diversity, (https://www.cbd.int/sp/targets/default.shtml

Wahle, C., Lyons, S., 2003. Social Science Research Strategy for MPAs. National Marine Protected Areas Centre, MPA Science Institute, Santa Cruz, California.

Yates, K.L., 2014. View from the wheelhouse: Perceptions on marine management from the fishing community and suggestions for improvement. Marine Policy 48, 39-50.

Yates, K.L., Schoeman, D.S., 2015. Incorporating the spatial access priorities of fishers into strategic conservation planning and marine protected area design: reducing cost and increasing transparency. ICES Journal of Marine Science 72, 587-594.

Yates, K.L., 2018. Meaningful stakeholder participation in marine spatial planning with offshore energy. Pp 169-188. In Offshore Energy and Marine Spatial Planning. Editors Yates, K.L. and Bradshaw, CJA. Routledge, London. ISBN: 9781317356424 
1011 Figure 1. Map of study site, showing the Encounter Marine Park in green.

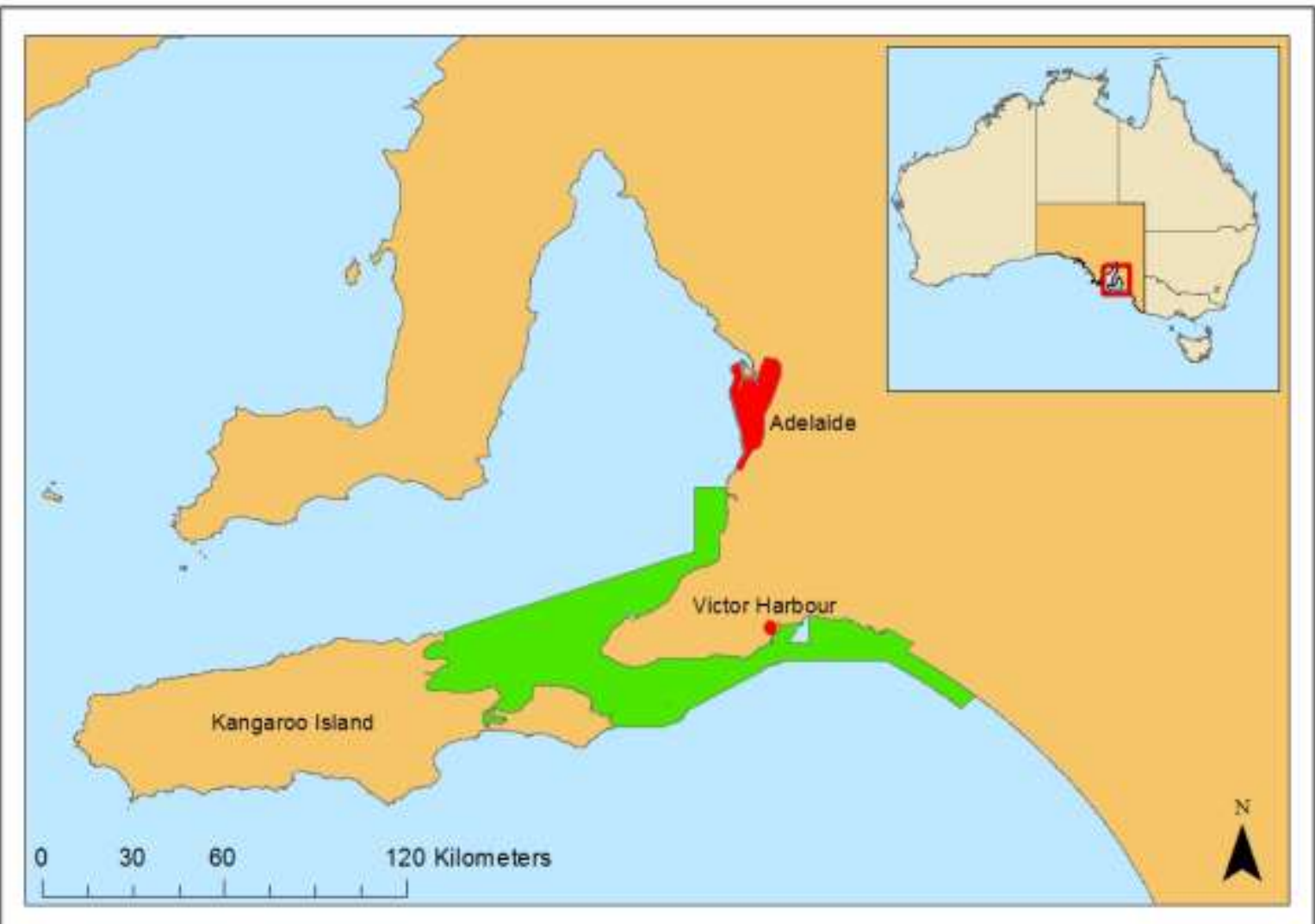

1013

1014

1015 Figure 2. Comparison of interviewees' ( $n=41)$ stated purpose of the Encounter Marine Park 1016 and how they would measure success of the MPA. 
1017
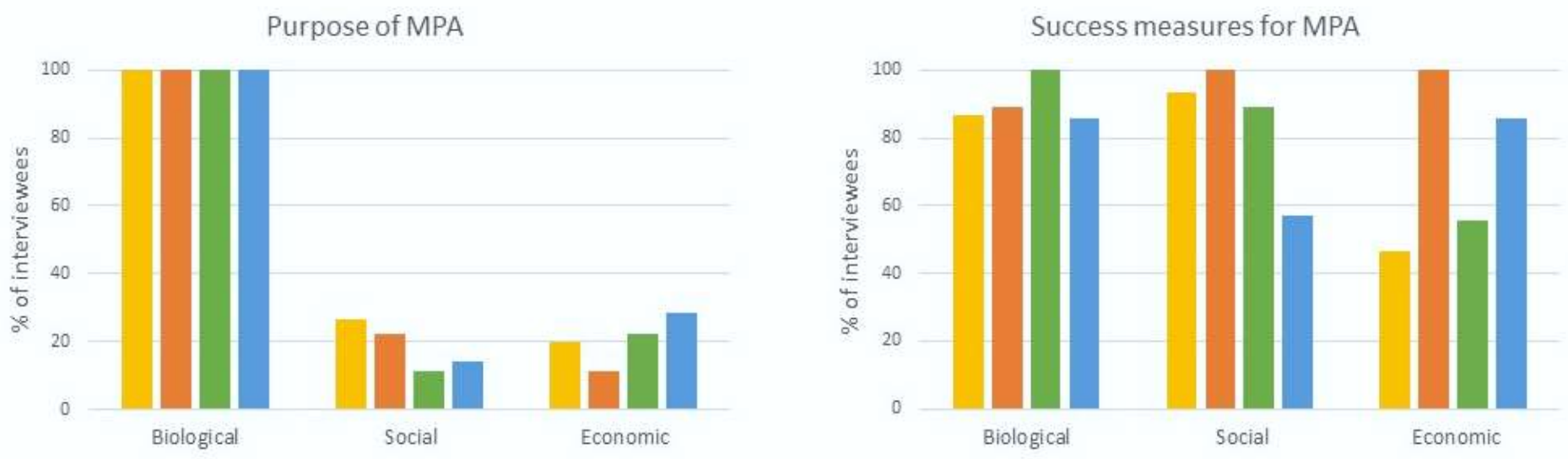

= State Government $=$ Local Government $=$ Conservation \& Community $\mathbf{m}$ Fishing 
1019 Table 1. Composition of the different stakeholder groups and number of individuals

1020 interviewed. For analysis the private consultant was included in conservation and community

1021 groups.

\begin{tabular}{|c|c|c|}
\hline Stakeholder Type & Sector/Division/Group & No. interviewed \\
\hline State Government & $\begin{array}{l}\text { Department of Environment Water \& Natural Resources } \\
\text { Primary Industries \& Regions South Australia } \\
\text { SA Tourism Commission } \\
\text { Department of State Development } \\
\text { Department of Transport } \\
\text { Natural Resource Management Division }\end{array}$ & 15 \\
\hline $\begin{array}{l}\text { Local Government } \\
\text { (Mayors, CEOs, } \\
\text { Councilors, } \\
\text { Environment Officers) }\end{array}$ & $\begin{array}{l}\text { City of Onkaparinga } \\
\text { District Council of Yankallilla } \\
\text { Alexandrina Council } \\
\text { City of Victor Harbor } \\
\text { Kangaroo Island Council }\end{array}$ & 9 \\
\hline $\begin{array}{l}\text { Conservation and } \\
\text { community groups }\end{array}$ & $\begin{array}{l}\text { 'Friends of' groups } \\
\text { Citizen Science groups } \\
\text { Volunteer groups }\end{array}$ & 9 \\
\hline Fisheries & $\begin{array}{l}\text { Commercial Fishing } \\
\text { Charter Boat Operators } \\
\text { Recreational Fishing }\end{array}$ & 7 \\
\hline Private consultant & Marine expertise & 1 \\
\hline & Total: & 41 \\
\hline
\end{tabular}

1023

1024

1025

1026 Table 2. Composition of the four focus groups and locations held.

\begin{tabular}{lll}
\hline Location & Stakeholder group & No. attendees \\
\hline Kangaroo Island & Fishing & 7 \\
Kangaroo Island & Conservation Interests & 8 \\
Yankalilla & Fishing & 8 \\
Victor Harbor & Conservation Interests & 9 \\
\hline Total & & 32 \\
\hline
\end{tabular}

1027 
Table 3. Breakdown of responses of individual interviewees $(n=41)$ and the four focus groups on what the purpose of Encounter Marine Park was and how they would measure the success of the Marine Park.

\begin{tabular}{|c|c|c|c|c|c|c|c|c|}
\hline & \multirow[b]{2}{*}{ Stakeholder group } & \multirow[b]{2}{*}{ (n) } & \multicolumn{3}{|c|}{ Purpose of park } & \multicolumn{3}{|c|}{ Measures of success } \\
\hline & & & Biological & Social & Economic & Biological & Social & Economic \\
\hline \multirow[t]{6}{*}{ Interviewees } & State Government & (15) & 15 & 4 & 3 & 13 & 14 & 7 \\
\hline & Local Government & (9) & 9 & 2 & 1 & 8 & 9 & 2 \\
\hline & Conservation \& Community & (9) & 9 & 1 & 2 & 9 & 8 & 5 \\
\hline & Fishing & (7) & 7 & 1 & 2 & 6 & 4 & 6 \\
\hline & Consultant & $(1)$ & 1 & 0 & 0 & 1 & 1 & 0 \\
\hline & Total & (41) & 41 & 8 & 8 & 37 & 36 & 20 \\
\hline \multirow[t]{3}{*}{ Focus groups } & Fishing & $(2)$ & 2 & 2 & 0 & 1 & 2 & 2 \\
\hline & Conservation \& Community & $(2)$ & 2 & 1 & 1 & 2 & 2 & 2 \\
\hline & Total & (4) & 4 & 3 & 1 & 3 & 4 & 4 \\
\hline
\end{tabular}


Table 4. Representative selection of measures to quantify MPA success, as suggested by interviewees and focus group participants. Measures are arranged by broad and then more specific indicator categories.

\begin{tabular}{|c|c|}
\hline Indicator category & Measures that could be used to quantify success \\
\hline $\begin{array}{l}\text { Biological } \\
\text { Biodiversity }\end{array}$ & $\begin{array}{l}\text { Species richness, overall abundance and biomass } \\
\text { Presence of threatened/endemic species }\end{array}$ \\
\hline Human pressure & $\begin{array}{l}\text { Number of boat strikes on megafauna reported } \\
\text { Extent of habitat damage/recovery }\end{array}$ \\
\hline $\begin{array}{l}\text { Economic } \\
\text { Added value }\end{array}$ & $\begin{array}{l}\text { Extent that local councils/towns advertise the marine park on their webpages } \\
\text { Extent to which local businesses use the marine park as a promotional tool }\end{array}$ \\
\hline $\begin{array}{l}\text { Existing/new } \\
\text { economic activities }\end{array}$ & $\begin{array}{l}\text { Commercial fishers profit margins } \\
\text { Number of individuals employed by commercial fisheries associated with MP } \\
\text { Total landed catch (within a given area) } \\
\text { Local businesses' financial support of community events } \\
\text { Price of fish } \\
\text { Diversity of employment opportunities (job adverts) }\end{array}$ \\
\hline $\begin{array}{l}\text { New economic } \\
\text { activities }\end{array}$ & $\begin{array}{l}\text { Investments in new businesses associated with marine environment } \\
\text { Number and amount of grants provided to support new marine park-related } \\
\text { businesses }\end{array}$ \\
\hline $\begin{array}{l}\text { Social } \\
\text { Community support }\end{array}$ & $\begin{array}{l}\text { If marine park is an election issue } \\
\text { Number of negative articles vs number of positive articles in local media } \\
\text { Levels of vandalism to marine park signs/other marine park-affiliated property }\end{array}$ \\
\hline Stewardship & $\begin{array}{l}\text { Number of partnerships between government authority and local } \\
\text { industries/indigenous groups/research institutions/NGOs }\end{array}$ \\
\hline $\begin{array}{l}\text { Government } \\
\text { support }\end{array}$ & Proportion of community events attended by marine park representative \\
\hline $\begin{array}{l}\text { Government } \\
\text { support, Longevity }\end{array}$ & Number/area of marine parks maintained/increased in successive political cycles \\
\hline $\begin{array}{l}\text { Community support } \\
\& \text { community use }\end{array}$ & $\begin{array}{l}\text { Number of people from the local community attending marine park-based events } \\
\text { Reports of suspected non-compliance by local businesses and/or residents }\end{array}$ \\
\hline $\begin{array}{l}\text { Education \& public } \\
\text { awareness }\end{array}$ & Amount of marine park education material included by tour operators in their tours \\
\hline $\begin{array}{l}\text { Stewardship, } \\
\text { Community support }\end{array}$ & $\begin{array}{l}\text { The number of groups/individuals that volunteer for marine park-related work } \\
\text { Diversity of citizen science opportunities available }\end{array}$ \\
\hline
\end{tabular}

\section{Socio-economic}

Existing economic activities, Recreation \& community use
Number of boats purchased

Number of diving/wildlife-watching/similar trips occurring within park boundaries Number of recreational fishers visiting region

Number of tourists visiting regional areas for marine environment-based use Occupancy rate of holiday homes

Number of visitor nights 
